\title{
Menstruation from the pfannenstial scar: A case of rare presentation of atypical endometriosis
}

\author{
Ahmad Akram Omar, Mohd Shukri Othman, Pek Sung Hoo, \\ Erinna Mohamad Zon, Ahmad Amir Ismail, Rahimah Abdul Rahim, \\ Nik Rafiza Afendi, Adibah Ibrahim
}

\begin{abstract}
Introduction: Endometriosis is the presence of functioning endometrium (gland and stroma) in sites other than uterine mucosa, usually in the pelvis, causing dysmenorrhea, dyspareunia, menstrual irregularities, and infertility. Case Report: A 27-year-old, had caesarean section 11 months ago presented to Obstetrics and Gynaecology clinic with cyclical bleeding from her surgical scar from ten months. She noted bleeding from the small nodule over the healed pfannenstial scar on day of her menses. Examination revealed a small reddish nodule $0.5 \mathrm{~cm} x 0.5 \mathrm{~cm}$, non-tender, with two blackish dots on it. Transabdominal ultrasound examination revealed that the nodule confined at the subcutaneous tissue, above the rectus.
\end{abstract}

Ahmad Akram Omar ${ }^{1}$, Mohd Shukri Othman², Pek Sung $\mathrm{Hoo}^{3}$, Erinna Mohamad Zon ${ }^{4}$, Ahmad Amir Ismail ${ }^{1}$, Rahimah Abdul Rahim ${ }^{1}$, Nik Rafiza Afendi ${ }^{1}$, Adibah Ibrahim ${ }^{5}$

Affiliations: ${ }^{1}$ Senior lecturer, Obstetrics and Gynaecology Department, School of Medical Science, University Sains Malaysia, Kota Bharu, Kelantan, Malaysia; ${ }^{2}$ Professor, Obstetrics and Gynaecology Department, School of Medical Science, University Sains Malaysia, Kota Bharu, Kelantan, Malaysia; ${ }^{3}$ Clinical lecturer, Obstetrics and Gynaecology Department, School of Medical Science, University Sains Malaysia, Kota Bharu, Kelantan, Malaysia; ${ }^{4}$ Specialist trainee, Obstetrics and Gynaecology Department, School of Medical Science, University Sains Malaysia, Kota Bharu, Kelantan, Malaysia; ${ }^{5}$ Associate Professor, Obstetrics and Gynaecology Department, School of Medical Science, University Sains Malaysia, Kota Bharu, Kelantan.

Corresponding Author: Pek Sung Hoo, Clinical lecturer, Obstetrics and Gynaecology Department, School of Medical Science, University Sains Malaysia, Kota Bharu, Kelantan, Malaysia.

Received: 20 August 2017

Accepted: 26 December 2017

Published: 11 April 2018
Diagnosis of scar endometriosis was made. She had wide local excision and recovered well. The histological examination was consistent with scar endometriosis. Conclusion: Scar endometriosis is a very rare condition. Women in the reproductive age with swelling, pain and discharge at the scar following surgery should be suspected for scar endometriosis.

Keywords: Caesarean section, Endometriosis, Pfannenstial scar, Scar endometriosis

\section{How to cite this article}

Omar AA, Othman MS, Hoo PS, Zon EM, Ismail AA, Rahim RA, Afendi NR. Menstruation from the pfannenstial scar: A case of rare presentation of atypical endometriosis. J Case Rep Images Obstet Gynecol 2018;4:100036Zo8AO2018.

Article ID: 100036Zo8AO2018

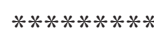

doi: 10.5348/100036Zo8AO2018CR

\section{INTRODUCTION}

Endometriosis is the presence of functioning endometrium (gland and stroma) in sites other than uterine mucosa, usually in the pelvis, causing dysmenorrhea, dyspareunia, menstrual irregularities, and infertility [1]. It is not a neoplastic condition, although malignant transformation is possible. Endometriosis is a disease of contrast. It is a benign but locally invasive, disseminates widely. Cyclic hormones stimulate growth but continuous hormones suppress it. Scar endometriosis is rare with incidence of $0.3-1 \%$ [2]. It usually manifest 


\section{EDORIUM Journals}

\section{www.edoriumjournals.com/case-reports/jcrog}

as discrete mass near surgical or procedural scars such as caesarean section, hysterectomy and episiotomy. [3]. A palpable subcutaneous mass near surgical scars associated with cyclic pain and swelling during menses is the most frequent clinical presentation [4]. Some even manifest as cyclical bleeding during menses. Hereby we report a case of cyclical bleeding scar endometriosis following caesarean section.

\section{CASE REPORT}

A 27-year-old Malay lady, whose last child birth was 11 months ago presented to Obstetrics and Gynaecology clinic with cyclical bleeding from her surgical scar for ten months. She had emergency lower segment caesarean section (EMLSCS) for poor progress of labour and the surgery was uncomplicated. She regained her menses after two months and noted bleeding from the small nodule on day one menses. On subsequent months bleeding became longer till day three menses. She denied dysmenorrhea, dyspareunia, and intermenstrual bleeding. Examination of the abdomen revealed a small reddish nodule $0.5 \mathrm{~cm}$ xo.5cm, non-tender, with two blackish dots on it, well defined lesion and non-mobile (Figure 1).

Transabdominal ultrasound examination revealed that the nodule was confined at the subcutaneous tissue, above the rectus. Diagnosis of scar endometriosis was made based on the clinical presentation and ultrasound examination. Subsequently, the patient underwent excision of scar endometriosis. The excision was made around the mass with a margin of $1 \mathrm{~cm}$ circumferential and $2 \mathrm{~cm}$ depth (Figure 2).

The histological finding was consistent with scar endometriosis. Postoperative recovery was uneventful and patient was discharged without medication. At three months follow-up, the patient was asymptomatic.

\section{DISCUSSION}

Endometriosis is the presence of functioning endometrium (gland and stroma) in sites other than uterine mucosa, usually in the pelvis, causing dysmenorrhea, dyspareunia, menstrual irregularities, and infertility [1]. This is the first occurrence of scar endometriosis at our center $[4,5]$. Scar endometriosis is rare with incidence of $0.3-1 \%$ [2]. It was postulated to occur as the result of mechanical transplant of the endometrium or placenta cell at the incision site during the operation [4]. Endometrial cells in early stage of wound healing might benefit with protective barrier and nutrition source provided by clot formation. With the effect of angiogenesis and stimulation of oestrogen, the disease might progress further.

Careful history and physical examination are important to diagnose the disease. Symptoms varies such as cyclical change in swelling size, bleeding or

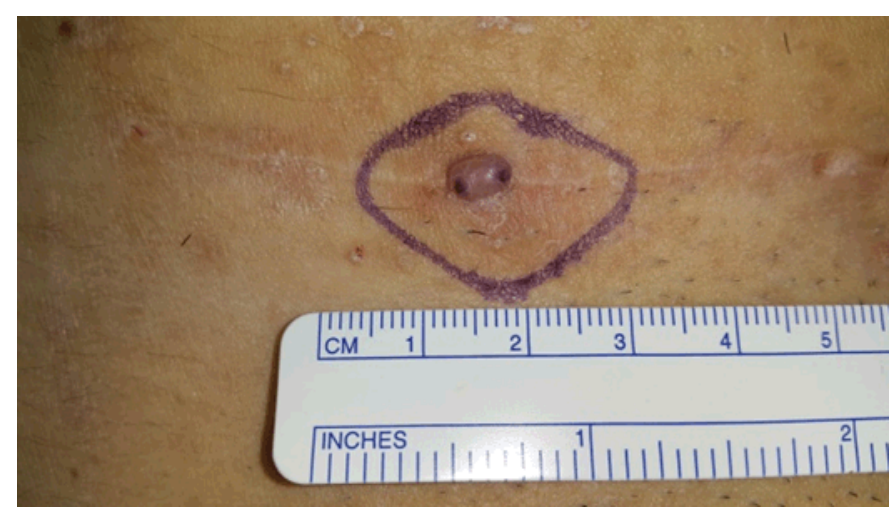

Figure 1: Small nodule at the region of caesarean section scar.

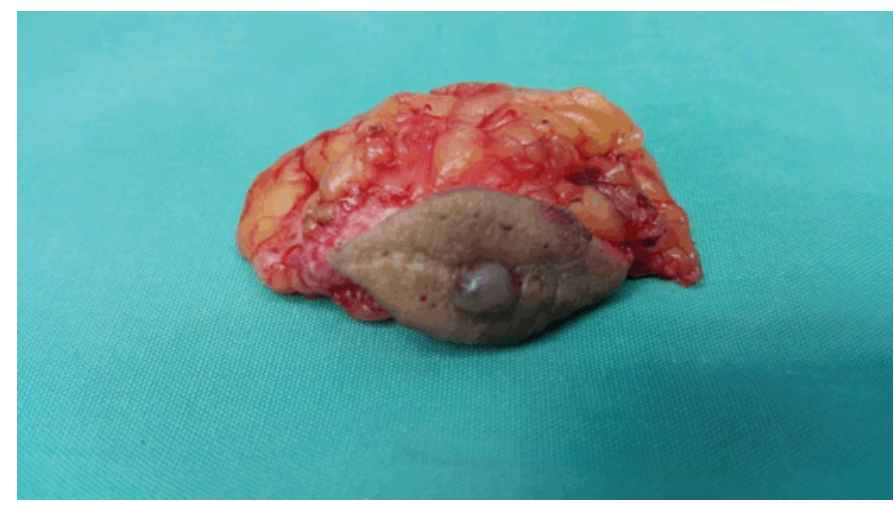

Figure 2: Tissue removed after excision.

discharge from the scar and abdominal wall pain and is always misdiagnosed as the incidence is extremely low, and symptoms may be easily dismissed by the patient. In one case, series of six cases by Poonam Goel at el, none of the patient had symptoms of pelvic endometriosis [9]. The incidence of concomitant pelvic endometriosis with scar endometriosis has been reported to be from $14.3 \%$ to $26 \%$ [2]. Ideally, all patients should be examined for concomitant pelvic endometriosis. When a proper diagnosis cannot be achieved, scar endometriosis can be easily mixed with other surgical conditions like hematoma, neuroma, hernia, granuloma, abscess, scar tissue, neoplastic tissue, or even metastatic carcinoma, which is a simple excuse to refer the patient to the general surgeon [8,9]. Often, the diagnosis of endometriosis is not suggested until after a biopsy and histology examination has been performed. Correct preoperative diagnosis is achieved in $20 \%$ to $50 \%$ of these patients $[2,3,4]$.

Imaging procedures help, rather than confirm, in obtaining a differential diagnosis. Ultrasonography is the best and most commonly used investigation tool for abdominal masses, given its practicality and lower cost. Francica et al showed diagnostic USG features of scar endometriosis as (i) a hypoechoic echoes, (ii) regular margin, often speculated, infiltrating the adjacent tissue and (iii) a hypoechoic ring of variable width and continuity [6]. Fine-needle aspiration cytology (FNAC) 


\section{EDORIUM Journals}

was reported in some studies for confirming the diagnosis However, FNAC is not a liable method to make the diagnosis of scars, and surgeons must be aware of some diagnosis such as inguinal hernia and re-implantation of potential malignancies during process. Theoretically, this procedure has the potential to seed the needle tract with cell and cause recurrence, especially within concomitant intra-pelvic endometriosis $[3,5,6]$. It might be benefit in the cases of large masses, doubtful diagnosis, and atypical clinical presentations.

Local wide excision, with at least a $1 \mathrm{~cm}$ margin, is an accurate treatment choice of scar endometriosis and also for recurrent lesions [2-4, 10, 11]. It is often misdiagnosed entity and commonly occurs after caesarean delivery, hysterostomy, hysterectomy and laparotomy [4, 5, 12]. Recurrence of scar endometriosis seldom happens with only a few cases reported. As expected, the larger and deeper lesions to the muscle or the fascia are more difficult to excise completely. In large lesions, complete excision of the lesion may entail a synthetic mesh placement or tissue transfer for closure after resection $[2,3,11]$. Medical therapy with danazol, progesterone, and GnRH produces only partial recovery, and mostly recurrence occurs after cessation of the treatment with extreme side effects [7]. The cause of recurrence might be incomplete initial incision or spreading of endometriosis during manipulation.

Histology is the hallmark of diagnosis. It is confirmed by presence of endometrial glands, stroma, and hemosiderin pigment [1].

Numerous measures have been proposed to prevent scar endometriosis. Wasfie et al suggested a method to prevent such iatrogenic implants by careful cleaning and vigorous irrigation of the abdominal wall wound with a high-jet saline solution before closure [13].

\section{CONCLUSION}

In conclusion, scar endometriosis is a rare condition but with significant quality of life disturbance. Therefore, any women in the reproductive age presented with painful swelling and discharge from the scar following obstetric surgery, scar endometriosis should be suspected. Wide local excision is the procedure of choice for both diagnostic and therapeutic purposes.

\section{REFERENCES}

1. Pauerstein CJ. Clinical presentation and diagnosis. In: Schenken RS, editor. Endometriosis: Contemporary Concepts in Clinical Management. Philadelphia, PA: JB Lippincott; 1989. p. 127-44.

2. Bergqvist A. Different types of extragenital endometriosis: A review. Gynecol Endocrinol 1993 Sep;7(3):207-21.

3. Steck WD, Helwig EB. Cutaneous endometriosis. Clin Obstet Gynecol 1966 Jun;9(2):373-83.
4. Koger KE, Shatney CH, Hodge K, McClenathan JH. Surgical scar endometrioma. Surg Gynecol Obstet 1993 Sep;177(3):243-6.

5. Patterson GK, Winburn GB. Abdominal wall endometriomas: Report of eight cases. Am Surg 1999 Jan;65(1):36-9.

6. Francica G, Giardiello C, Angelone G, Cristiano S, Finelli R, Tramontano G. Abdominal wall endometriomas near cesarean delivery scars: Sonographic and color doppler findings in a series of 12 patients. J Ultrasound Med 2003 Oct;22(10):10417.

7. Rivlin ME, Das SK, Patel RB, Meeks GR. Leuprolide acetate in the management of cesarean scar endometriosis. Obstet Gynecol 1995 May;85(5 Pt 2):838-9.

8. Rani PR, Soundararaghavan S, Rajaram P. Endometriosis in abdominal scars: Review of 27 cases. Int J Gynaecol Obstet 1991 Nov;36(3):215-8.

9. Goel P, Devi L, Tandon R, Saha PK, Dalal A. Scar endometriosis - a series of six patients. Int J Surg 2011;9(1):39-40.

10. Ding DC, Hsu S. Scar endometriosis at the site of cesarean section. Taiwan J Obstet Gynecol 2006 Sep;45(3):247-9.

11. Marsden NJ, Wilson-Jones N. Scar endometriosis: A rare skin lesion presenting to the plastic surgeon. J Plast Reconstr Aesthet Surg 2013 Apr;66(4):e111-3.

12. Uzunçakmak C, Güldaş A, Ozçam H, Dinç K. Scar endometriosis: A case report of this uncommon entity and review of the literature. Case Rep Obstet Gynecol 2013;2013:386783.

13. Wasfie T, Gomez E, Seon S, Zado B. Abdominal wall endometrioma after cesarean section: A preventable complication. Int Surg 2002 Jul-Sep;87(3):175-7.

$* * * * * * * * *$

\section{Author Contributions}

Ahmad Akram Omar - Substantial contributions to conception and design, Acquisition of data, Drafting the article, Revising it critically for important intellectual content, Final approval of the version to be published Mohd Shukri Othman - Substantial contributions to conception and design, Acquisition of data, Drafting the article, Final approval of the version to be published Pek Sung Hoo - Substantial contributions to conception and design, Acquisition of data, Drafting the article, Revising it critically for important intellectual content, Final approval of the version to be published

Erinna Mohamad Zon - Substantial contributions to conception and design, Analysis and interpretation of data, Drafting the article, Final approval of the version to be published

Ahmad Amir Ismail - Substantial contributions to conception and design, Acquisition of data, Drafting the article, Revising it critically for important intellectual content, Final approval of the version to be published Rahimah Abdul Rahim - Substantial contributions to conception and design, Acquisition of data, Drafting the article, Final approval of the version to be published 


\section{EDORIUM Journals}

J Case Rep Images Obstet Gynecol 2018;4:100036Zo8AO2018. www.edoriumjournals.com/case-reports/jcrog

Nik Rafiza Afendi - Substantial contributions to conception and design, Acquisition of data, Drafting the article, Final approval of the version to be published Adibah Ibrahim - Substantial contributions to conception and design, Acquisition of data, Drafting the article, Final approval of the version to be published

\section{Guarantor of Submission}

The corresponding author is the guarantor of submission.

\section{Source of Support}

None

\section{Consent Statement}

Written informed consent was obtained from the patient for publication of this case report.

\section{Conflict of Interest}

Authors declare no conflict of interest.

\section{Copyright}

(C) 2018 Ahmad Akram Omar et al. This article is distributed under the terms of Creative Commons Attribution License which permits unrestricted use, distribution and reproduction in any medium provided the original author(s) and original publisher are properly credited. Please see the copyright policy on the journal website for more information.
Access full text article on other devices

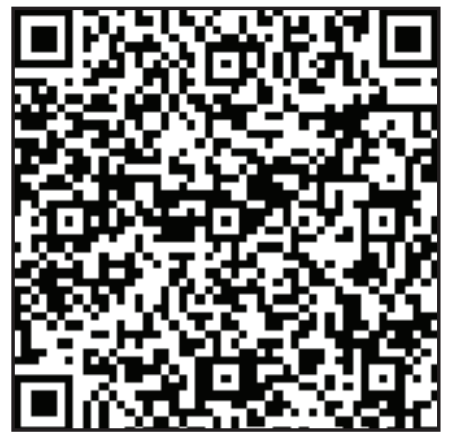

Access PDF of article on other devices

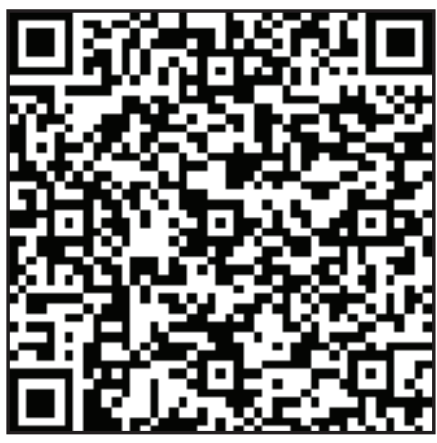

